\title{
Correlation of blood gas status with the mortality of neonates admitted in ICU
}

\author{
M M Yusuf ${ }^{1}$, M A K A Chowdhury ${ }^{2}$
}

\begin{abstract}
Background : Blood gas abnormalities are frequently encountered in sick neonates admitted in ICU. They contribute significantly to mortality. Therefore, blood gas status is a helpful indicator of the condition of sick neonate.

Objective : To study the correlation between blood gas status and mortality of neonates admitted in ICU.

Methods : This observational study was carried out at the ICU of Dhaka Shishu Hospital (DSH) from January 2014 to July 2014. Total 121 neonates were enrolled according to inclusion criteria and analyzed their blood gas status which were correlated with the mortality of neonates.

Results : Perinatal asphyxia (PNA) was common disorder with the highest mortality in neonate followed by sepsis and pneumonia. Significant association between mortality with lower $\mathrm{pH}, \mathrm{PCO}_{2}$ and higher base excess was observed. Metabolic acidosis was the most common acid-base disorder.

Conclusion : Low $\mathrm{pH}, \mathrm{PCO}_{2}$ and more base excess are predictor of mortality in this group of neonate. Initial acid-base derangement significantly correlates with the mortality of critically ill neonates requiring ICU care.

Keywords : Blood gas analysis, perinatal asphyxia, metabolic acidosis.

DOI: http://dx.doi.org/10.3329/nimcj.v9i1.35924

Northern International Medical College Journal Vol. 9 No. 1 July 2017, Page 261-263
\end{abstract}

\section{Dr. Mir Mohammad Yusuf Assistant Professor Paediatric Medicine Bangladesh Institute of Child Health (BICH) \\ Dhaka Shishu (Children) Hospital}

2 Prof. MAK Azad Chowdhury Professor and Head Dept. of Neonatology Bangladesh Institute of Child Health (BICH)

Dhaka Shishu (Children) Hospital

Correspondence

Dr. Mir Mohammad Yusuf

Assistant Professor

Paediatric Medicine

Bangladesh Institute Child Health (BICH)

Dhaka Shishu (Children) Hospital

e-mail:dr.miryusufpavel@gmail.com

\section{Introduction}

Understanding of hemoglobin-oxygen interactions and gas exchange provide cornerstone for clinical success to neonatal care. Critically ill neonate commonly have acid-base disorder which is a valuable indicator to a pediatrician about patient assessment, therapeutic decision and prognosis of the patient. ${ }^{1}$ Blood gas analysis help in the diagnosis of metabolic and respiratory acidosis associated with birth process and with postnatal adaptation to air breathing. ${ }^{1-2}$ The cardiovascular system undergoes changes after birth, respiratory gas exchange begins instead of formerly placental function, must be established by the lungs within minutes. Therefore, frequent and serious difficulties in cardio-respiratory adaptation in perinatal and neonatal periods are not surprising. ${ }^{3}$

Blood gas analysis provides $\mathrm{pH}, \mathrm{PCO}_{2}$ from which $\left(\mathrm{HCO}_{3}{ }^{-}\right)$and base excess (BE) can be derived. ${ }^{4,5}$ Moreover, it is easily understandable and widely used at the bed side management. ${ }^{6}$ This traditional approaches to analysis of acid-base status adapted from Handerson-Hasselbach equation mathematically links the variables of $\mathrm{pH}, \mathrm{PCO}_{2}$ and bicarbonate concentration $\left(\mathrm{HCO}_{3}\right)^{7}$

The $\mathrm{PCO}_{2}$ concentration in a given patient reflects the balance between metabolic production of $\mathrm{CO}_{2}$ and excretion by ventilation. The normal range of $\mathrm{PCO}_{2}$ after the first hour of life can be considered $35-45 \mathrm{mmHg}, \mathrm{pH}$ value for a specific situation may be related to higher or lower $\mathrm{PCO}_{2}$. Elevation of $\mathrm{PCO}_{2} 10 \mathrm{mmHg}$ decreases $\mathrm{pH}$ by 0.08 while decrease of $\mathrm{PCO}_{2}$ $10 \mathrm{~mm} \mathrm{Hg}$, increases $\mathrm{pH}$ by $0.08 .8,9$

In this regard marked structural and functional difference found in children in comparison to adults i.e children have narrow distal airways. Therefore, atelectasis develop quickly resulting in rapid-onset of hypercarbia and hypoxia. Chest wall is compliant and respiration is less efficient; the respiratory center is immature, hypoxia and hypercarbia lead to decreased respiratory drive. In addition they have reactive vascular bed to 
maintain their blood pressure until late, therefore one cannot rely on hypotension to diagnose shock as in adults. ${ }^{10}$ Hence blood gases provide essential information on acid-base status in critically ill neonates and predict their mortality.

Perinatal asphyxia and neonatal sepsis both are common occurrence in neonate and major health problems in Bangladesh like other developing countries and devastating cause of mortality. The acid-base abnormalities are common in perinatal asphyxia and neonatal sepsis, which need more vigorous measures to reduce their mortality in an emergency situation. Sometimes, perinatal asphyxia occurs when there is inadequate placental gas exchange to meet ongoing tissue needs for oxygen consumption and $\mathrm{CO}_{2}$ elimination. The combination of lactic acidosis, product of anaerobic metabolism and $\mathrm{CO}_{2}$ accumulation results in a mixed acidosis. It results most commonly from a drop in maternal blood pressure or some other substantial interference with blood flow to the infant's brain during delivery. This can occur due to inadequate circulation or perfusion, impaired respiratory effort, or inadequate ventilation. ${ }^{11} \mathrm{An}$ infant suffering from severe perinatal asphyxia usually has cyanosis, less perfusion, poor responsiveness reduce muscle tone and poor respiratory effort as reflected in low APGAR score (5minute). Extreme degrees of asphyxia can cause cardiac arrest and death. Immediately after birth asphyxia, hypothermia generally lower metabolic rates and diminishes the glutamate levels in brain. ${ }^{12-13}$ In neonatal sepsis, unstable temperature and less tissue perfusion leading to derangement of acid-base balance. Hence, it is desirable to have values corrected for patient temperature. Temperature affects $\mathrm{pH}, \mathrm{PCO}_{2}$ and $\mathrm{PO}_{2}$.

This study was carried out in neonates with various ailments attending ICU at a tertiary care hospital of Dhaka, Bangladesh. The objective was to study acid-base status in common neonatal disease such as perinatal asphyxia, sepsis, pneumonia etc. and its relation with mortality.

\section{Patients and Methods}

This observational study was conducted at ICU, Dhaka Shishu (Children) Hospital during the period of January to July 2014. For each neonate, a detailed history from the mother or other care-giver was recorded in a preset questionnaire along with particulars of the neonates. Neonatal history included time of first cry or breathing immediately after birth, apnoea/cyanosis, convulsion, reluctant to feed and bleeding manifestation. Maternal history included antenatal care, prolonged rupture of the membranes ( $>12$ hours before delivery was considered), prolonged second stage of labour, gestational age was determined from maternal records. Total 161 neonates admitted during this period among these 40 were excluded from this study due to any congenital anomaly,severely jaundiced due to blood group incompatibilities or received LAMA (Left against medical advice) and rest 121 were included in the study. Before enrollment parent of each child was given a detail explanation about the nature and purpose of the study. The study obtained ethical clearance by Bangladesh Institute of Child Health, Dhaka Shishu Hospital.

Enrolled neonates were analyzed for the blood gas status as well as baseline investigations as a part of management. With all aseptic precaution blood sample was obtained in the disposable syringe. Blood gas analyzer (Gastal-600) based on the principle of potentiometry analyzed $\mathrm{pH}, \mathrm{PCO}_{2}$ by respective electrodes. Base excess ( $\mathrm{BE})$ and $\left(\mathrm{HCO}_{3}-\right)$ were calculated from the parameters of $\mathrm{pH}$ and $\mathrm{PCO}_{2}$ which were provided by the analyzer. All data were analyzed by SPSS version 20 .

\section{Results}

In this study, 121 neonates (0-28 days), median age was 7 days. 84 neonates were male and 37were female, ratio 2.27:1. Among the admitted neonates most cases were PNA and Sepsis (Fig. 1).

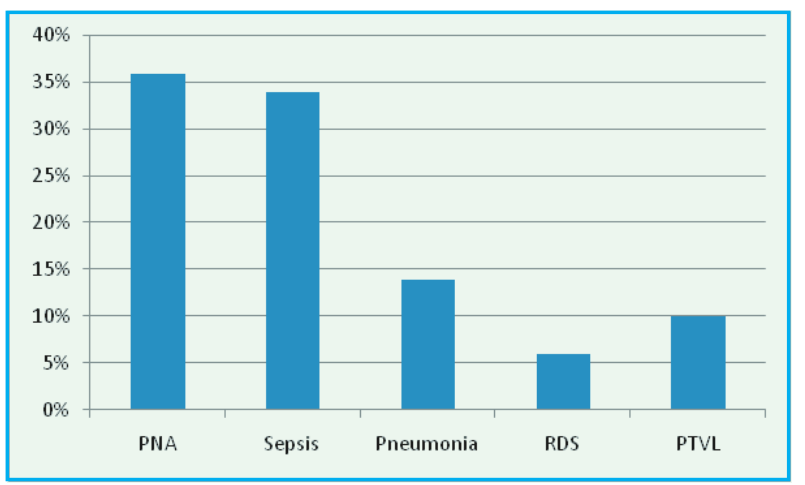

Fig 1: Diseases of ICU admitted neonate

For the analysis of data study neonates were divided into survival and non-survival groups. Initial observation of blood gas status in perinatal asphyxia and sepsis among survivors and non-survivors showed non- Survivors had less $\mathrm{pH}$ and more base excess level than survivors which were statistically significant (Table I). There was also statistical significant difference of blood gas status in perinatal asphyxia and sepsis among survivors and non-survivors at the end of the study. Nonsurvivors had less $\mathrm{pH}, \mathrm{HCO}_{3}, \mathrm{PCO}_{2}$ and more base excess level than survivors which were statistically significant (Table II).

$\begin{array}{lccc}\text { Table I : Acid-base parameters in Survivors and Non-survivors (Initial) } & \begin{array}{c}\text { Survivors }(\mathbf{n}=\mathbf{7 1}) \\ \text { Mean } \pm \text { SD }\end{array} & \begin{array}{c}\text { Non-Survivors }(\mathbf{n}=\mathbf{5 0}) \\ \text { Mean } \pm \text { SD }\end{array} & \text { value } \\ & 7.36 \pm 0.1 & 7.3 \pm 0.19 & 0.011^{\mathrm{S}} \\ \mathrm{pH} & 31.69 \pm 11.54 & 33.63 \pm 17.48 & 0.466^{\mathrm{nS}} \\ \mathrm{PCO}_{2}(\mathrm{~mm} \mathrm{of} \mathrm{Hg}) & 17.95 \pm 10.4 & 0.961^{\mathrm{ns}} \\ \mathrm{HCO}_{3}(\mathrm{mmo} / \mathrm{L}) & 18.03 \pm 6.59 & -10.74 \pm 15.89 & 0.004^{\mathrm{S}} \\ \text { Base Excess } & -4.3 \pm 6.88 & & \end{array}$




$\begin{array}{lccc}\text { Table II : Acid base parameters in Survivors and Non-Survivors } & \begin{array}{c}\text { Survivors }(\mathbf{n}=\mathbf{7 1}) \\ \text { Mean } \pm \text { SD }\end{array} & \begin{array}{c}\text { Non-Survivors }(\mathbf{n}=\mathbf{5 0}) \\ \text { Mean } \pm \text { SD }\end{array} & \boldsymbol{P} \text { value } \\ & 7.4 \pm 0.07 & 7.21 \pm 0.22 & 0.001^{\mathrm{S}} \\ \mathrm{pH} & 41.41 \pm 13.23 & 26.39 \pm 12.12 & 0.007^{\mathrm{S}} \\ \mathrm{PCO}_{2}(\mathrm{~mm} \mathrm{of} \mathrm{Hg}) & 28.21 \pm 9.37 & 18.71 \pm 8.34 & 0.013^{\mathrm{S}} \\ \mathrm{HCO}_{3}(\mathrm{mmo1} / \mathrm{L}) & -3.82 \pm 4.51 & -13.21 \pm 12.4 & 0.001^{\mathrm{S}} \\ \text { Base Excess } & & & \end{array}$

\section{Discussion}

The study was carried out on the basis of neonates suffering from a wide variety of ailments attending ICU care. The selection was unbiased. Preponderance of males in this age group. Suffering from perinatal asphyxia, in accordance with the epidemiological pattern having the highest admission in the ICU was observed.

Arterial blood gas (ABG) sampling represents the gold standard method for acquiring patients acid-base status. Palsdottir $\mathrm{K}$ et al. evaluated the association between lower umbilical artery $\mathrm{pH}$, more base deficit, and the development of hypoxic ischemic encephalopathy. ${ }^{14}$ The majority of neonates with death had an arterial $\mathrm{pH}<7.00$, therefore this would have had to occur in the majority of babies termed as acidosis paradox. ${ }^{15}$ Acid-base disorders in critically ill neonatal ICU patients and predicting survival by the presence of deranged acid-base variables. ${ }^{16}$ In this study lower mean $\mathrm{pH}$ in non-survivors was around 7.

An abnormal cord pH less than 7.2 immediately after birth can be used as a prognostic factor for unfavorable short term outcome in newborns. Now recommended in all high risk deliveries by both the British and American colleges of Obstetrics and Gynaecology. ${ }^{17}$ Williams KP et al. suggest that severe fetal academia identified by a pH less than 7.0 was the most umbilical blood gas variable for predicting early onset of worst outcome e.g., seizures or mortality. ${ }^{18}$ Goodwin TM et al. stated with worsening acidosis, mortality increases. They found that at $\mathrm{pH}<7.00$ mortality occurs in $12 \%, 33 \%$ with cord $\mathrm{pH}<6.9,60 \%$ with $\mathrm{pH}<6.8,80 \%$ with $\mathrm{pH}<6.7$. No infant was live born with $\mathrm{pH}<6.6 .^{19}$

Lekhwani S et al, \&Broder $\mathrm{G}$ et al. showed significant correlation between outcome and critical value of $\mathrm{pH}<7.2$ were associated with increase patient mortality. ${ }^{20}$

In sepsis, metabolic acidosis was found to be compensated by respiratory alkalosis. In this study low $\mathrm{PCO}_{2}$ and $\mathrm{HCO}_{3}$ were statistically significant in non-survivors compared with survivors. PCO2 provides the most accurate determinations of alveolar ventilation. ${ }^{8}$ This study has shown that metabolic acidosis (BE $<5 \mathrm{mmol} / \mathrm{L}$ ) is one of the most frequent acid-base disorder occurring in non-survivors, similar to various studies (Lekhwani $S$ et al.). ${ }^{20}$ which remains a powerful marker of poor prognosis in critically ill patients.

Consequently, the management of acid-base disorder always demands precise diagnosis and treatment of the underlying disease, it requires steps to combat the deviation to reduce the mortality. ${ }^{21}$ Nana $W$ et al. showed low $\mathrm{pH}$ and high base deficit alone or in combination reflect an impaired condition e.g., bad outcome parameter at birth. ${ }^{22}$ Similar to the present study, lower $\mathrm{pH}$ and higher base excess in non-survivors compared with survivors.

\section{Conclusion}

Blood gas status is a helpful indicator of the condition of sick neonate. Low pH, low $\mathrm{PCO}_{2}$ and more base excess are predictor of mortality in this age group. Initial acid-base derangement significantly correlates with the ultimate outcome of critically ill neonates of ICU.

\section{References}

1. James $L S$, Prince DA, Apgar W. The acid-base status of human infants in relation to birth asphyxia and the onset of respiration. The Journal of Pediatrics 1958;52: 379-94.

2. Gunnerson KJ. Clinical review: The meaning of acid-base abnormalities in the intensive care unit Part I epidemiology. Critical Care2005;9:508-16.

3. Orozco-Gregorio $H$, Mota Rojas D, Alonso M. Importance of blood gas measurements in perinatal asphyxia and alternatives to restore the acid-base balance status to improve the newborn performance. American Journal of Biotechnology and Biochemistry 2007;3:131-40.

4. Quigley R, Baum M. Neonatal acid-base balance and disturbances. Semi Perinatol2004;28:97-102.

5. Sekaran DV, Subramanyam L, Balonchandran A. Arteral Blood Gas Analysis in clinical practice. Indian paeditrics2001;38:1116-28.

6. Kellum JA. Clinical Review: reunification of acid-base physiology. Critical Care2005; 9:500-07.

7. Henderson J. The theory of neutrality regulation in the animal organism. American Journal Physiology1908;21:427-28.

8. Deorori AK. Blood gas analysis. AIIMS2008;3:1-41.

9. Cole $\mathrm{CH}$, Wright KW, Tarnow-Mordi W, Phelps DL. Resolving our uncertainty about oxygen therapy. Pediatrics2003;112:1415-19.

10. Otieno H, Were E, Ahmed I, Charvo E, Brent A, Maitland K. Are bed side features of shock reproducible between different observers? Arch Dis Child2004;89:977-99.

11. Barkorich, et al. Brain damage from perinatal asphyxia: correlation of MR findings with gestational age. American Journal of Neuroradiology2008;6:3-27.

12. Engidawork $E$, et al. Comparison between hypothermia and glutamate antagonism treatments on the immediate outcome of perinatal asphyxia. Exp Brain Res20012;138:375-83.

13. Berger R, Garnier Y. Perinatal brain injyry. J Perinatal Med2000;28:261-85.

14. Palsdottir K. Thorkelsson T, Dagbjartsson A. Birth asphyxia, neonatal risk factors for hypoxic ischemic encephalopathy. Laenabladid2007;93:669-73.

15. HermansonMC.The acidosis paradox in asphyxia brain injury without coincident academia. Dev Med Child Neurology2003;45:353-56.

16. Ahmad I, Ahmed A ,Roy S. Acid-base disorders in critically ill neonatal ICU patients and predicting survival by the presence of deranged Acid-Base variables. Journal of Neonatal biology2015;5:207-15.

17. A Cog Committee on Obs. Practice. Umbilical cord blood gas status. Obstetric \& Gynaecology 2006;108:1319-1322.

18. Williams KP et al. The correlation of seizures in newborn infants with significant acidosis at birth with umbilical artery cord gas values. Obstet \& Gynecol 2002;100:557-60.

19. Goodwin TM et al. Asphyxia complications in the term newborn with with severe umbilical academia. Am J Obstet Gynecol 1992;167:1506-12.

20. LekhwaniS ,Shanker V, Gathwala G. Acid-base disorders in critically ill neonates. Indian J Critical Care Med 2010;14:65-69.

21. Horacio JA, Nicolos EM. Management of life threating acid-base disorders. New England Medicine 1998;338:26-34.

22. Nana W, Kamin K, Andreas H . Relation between umbilical cord blood pH,base excess, lactate and mortality.ActaObstetrica et GynaecologicaScandinavica 2010;89:1263-69. 